Pedagogía y Saberes No. 49

Universidad Pedagógica Nacional

Facultad de Educación. 2018, pp. 189-200

\title{
Discursos sobre aprendizagem no Brasil: uma análise da Revista Brasileira de Estudos Pedagógicos $(1944-1964)^{*}$
}

Artículo de investigación

Discursos sobre el aprendizaje en Brasil: un análisis de la Revista Brasileña de Estudios Pedagógicos (1944-1964)

Discourses on Learning in Brazil: An Analysis of the Brazilian Journal of Pedagogical Studies (1944 - 1964)

Para citar este artículo:

Enzweiler, D. (2018). Discursos sobre aprendizagem no Brasil: uma análise da Revista Brasileira de Estudos Pedagógicos (1944-1964). Pedagogía y Saberes, 49, 189-200.

* Este artigo é resultado de investigações realizadas pelo Grupo de Estudos e Pesquisa em Inclusão (GEPI) na Universidade do Vale do Rio dos Sinos (Unisinos), cujas pesquisas são financiadas pelo Conselho Nacional de Desenvolvimento Científico e Tecnológico (CNPq), no Brasil. Os resultados apresentados neste artigo estão relacionados a dois projetos recentemente desenvolvidos pelo GEPI: Inclusão e processos de subjetivação docente e Saberes docentes e Aprendizagem na Matriz de Experiência Inclusiva, ambos coordenados pela Prof. - Dr. - Maura Corcini Lopes.

** Estudiante de doctorado y becaria CAPES del PPGEdu de la Universidade do Vale do Rio dos Sinos-Unisinos. Magister en Educación e investigadora del Grupo de Estudos e Pesquisa em Inclusão-GEPI/Unisinos/CNPQ.

Correo electrónico: deiseandreia@gmail.com

Código ORCID: http://orcid.org/0000-0001-6971-937X 


\title{
Resumo
}

Este artigo, como resultado de investigação, objetiva apresentar e descrever como discursos sobre aprendizagem se articularam no contexto histórico brasileiro no período de 1944 a 1964, marcado por influências renovadoras do movimento da Escola Nova. Para elaboração desta descrição, utilizou-se a ferramenta conceitual do discurso. A apresentação do exercício investigativo está dividida em três focos distintos e complementares: um foco histórico; um foco metodológico e um foco analítico. Como resultado final, são apresentadas tendências dos discursos sobre aprendizagem no Brasil: aprendizagem como aprimoramento individual; aprendizagem como ajustamento social e aprendizagem como experiência. A partir disso, sustenta-se que o movimento escolanovista introduz diferentes compreensões acerca da aprendizagem visando uma renovação educacional no Brasil. Entretanto, tais apreensões não descartavam um tipo de condução pedagógica intencional, diferentemente de tendências pedagógicas atuais, marcadas por processos de naturalização e individualização da aprendizagem.

\section{Palavras-chave}

aprendizagem; ensino; Escola Nova; Brasil; condução pedagógica

\section{Resumen}

Este artículo, como resultado de investigación, tiene como objetivo presentar y describir cómo los discursos sobre aprendizaje se articularon en el contexto histórico brasileño en el periodo de 1944 a 1964, marcado por influencias renovadoras del movimiento de la Escuela Nueva. Para la elaboración de esta descripción, se utilizó la herramienta conceptual del discurso. La presentación del ejercicio investigativo está dividida en tres focos distintos y complementarios: un enfoque histórico; un enfoque metodológico y un enfoque analítico. Como resultado final, son presentadas algunas tendencias de los discursos sobre aprendizaje en el Brasil: aprendizaje como perfeccionamiento individual; aprendizaje como ajuste social y aprendizaje como experiencia. A partir de eso, se sustenta que el movimiento de la Escuela Nueva introduce diferentes comprensiones acerca del aprendizaje buscando una renovación educacional en el Brasil. No obstante, tales preocupaciones no descartaban un tipo de conducción pedagógica intencional, diferente de tendencias pedagógicas actuales, marcadas por procesos de naturalización e individualización del aprendizaje.

\section{Palabras clave}

aprendizaje; enseñanza; Escuela Nueva; Brasil; conducción pedagógica

\begin{abstract}
This article, as a result of research, aims to present and describe how discourses about learning were articulated in the Brazilian historical context from 1944 to 1964 , marked by renovating influences of the New School movement. The conceptual tool of discourse was used to do this description. The presentation of the investigative exercise is divided into three distinct and complementary cores: a historical approach, a methodological approach, and an analytical approach. As a final result, some trends of the discourses on learning in Brazil are presented: learning as individual improvement, learning as social adjustment, and learning as experience. Based on this, it is sustained that the New School movement introduces different understandings about learning, seeking a renovation of education in Brazil. However, such concerns did not rule out a type of intentional pedagogy, different from current pedagogical tendencies and marked by processes of naturalization and individualization of learning.
\end{abstract}

\section{Keywords}

learning; teaching; new school; Brazil; pedagogical conduction 


\section{Introdução}

Este artigo tem como objetivo apresentar e descrever discursos sobre aprendizagem no contexto histórico brasileiro no período de 1944 a 1964. Tal análise, resultado de uma pesquisa já concluída, será apresentada a partir de três focos: primeiramente, contextualizarei a pesquisa a partir de um foco histórico, no qual justifico o porquê da temática, da materialidade e do recorte histórico. Em seguida, passo para um foco metodológico, em que descreverei as operações metodológicas e a forma de organização, sistematização e exploração do material analisado a partir da ferramenta conceitual do discurso (Foucault, 2014). Por último, apresentarei um foco analítico da pesquisa, pontuando os resultados obtidos ao final do percurso investigativo.

Para a construção desta investigação, partiu-se de um tipo de diagnóstico do presente, especialmente a partir do que Biesta (2013a) define como a naturalização da aprendizagem. Para o autor, a aprendizagem tem sido compreendida como uma atividade que acontece por si, tal qual a respiração e digestão, por exemplo. Segundo Biesta, ao delimitarse a aprendizagem como uma atividade inerente ao ser humano, "produz-se um caminho escorregadio onde a aprendizagem primeiramente é equacionada à vida e necessariamente se torna um processo ao longo da vida" (p. 68). Em outro momento de suas análises sobre esta temática, Biesta (2013b) também aponta como um aspecto central para este processo de naturalização da aprendizagem o declínio de uma linguagem da educação e a ascensão de uma linguagem da aprendizagem. Segundo o autor, o "ensinar foi redefinido como apoiar ou facilitar a aprendizagem, assim como a educação é agora frequentemente descrita como propiciadora de oportunidades ou experiências de aprendizagem" (p. 32).

Considerando estas possibilidades para proceder à leitura do presente, especialmente a partir dos escritos de Biesta (2013a; 2013b), delimitou-se a construção de um cenário investigativo. Para tal realização, recorreu-se à variada pesquisa em legislação, bibliografia acadêmica e materiais jornalísticos no presente brasileiro. A partir deste mapeamento, identificou-se um processo de proliferação discursiva da aprendizagem. Ao pesquisar pela palavra aprendizagem no banco de teses e dissertações da CAPES ${ }^{1}$, percebe-se a presença da aprendizagem em áreas que minimamente se aproximam do campo educacional,

1 CAPes - Coordenação de Aperfeiçoamento de Pessoal de Nível Superior é uma fundação vinculada ao Ministério da Educação do Brasil que atua na expansão e consolidação da pós-graduação do país. como Sociais e Humanidades, Psicologia, Ensino de Ciências e Matemática e a própria Educação. Entretanto, são campos mais distantes destas áreas que se destacam por um tipo particular de apropriação da aprendizagem. Neste sentido, destacam-se áreas como a Administração/Gestão, as Ciências da Computação e a Engenharia/Tecnologias.

Ao minimamente adentrar nos trabalhos investigativos que se utilizam ou citam a aprendizagem, percebe-se que ela não é foco de problematização como temática. Também se evidenciou que seus usos são variados. Por exemplo, ao debruçar-me especificamente sobre as pesquisas na área das Ciências da Computação e que em algum momento apresentam a aprendizagem, percebem-se apropriações em que a aprendizagem ora aparece adjetivada (colaborativa, móvel, interpessoal, interativa), ora aparece adjetivando (formulação de objetos, conteúdos e assistentes virtuais de/para aprendizagem) e que ora aparece como algo que acontece em ambientes virtuais e redes.

Seguindo este tipo de buscas, também foram mapeados os repositórios virtuais de algumas universidades brasileiras. Nesta pesquisa, identificouse uma elevação considerável de trabalhos que de alguma forma abordavam a aprendizagem a partir dos anos 2000. Utilizando como exemplo o repositório da Universidade de São Paulo (USP), foi possível identificar que a aprendizagem passa a aparecer nas mais variadas áreas de pesquisa de forma recorrente desde o ano 2000, intensificando-se a partir de 2005 até 2015 , ano no qual foi realizada esta busca.

Tais exemplos, aparentemente singelos, aliaramse a leituras e estudos que têm desconfiado deste tipo de exaltação indiscriminada da aprendizagem no presente. Ao identificar a proliferação discursiva da aprendizagem, especialmente na virada do século Xx para o século XXI, pode-se caracterizar tal cenário a partir daquilo que Popkewitz, Olson e Petersson (2009, p. 80) denominam como sendo uma sociedade de aprendizagem: "Se a criança e o adulto, ao final do século XIX, foram pensados como sujeitos que internalizariam as narrativas sociais coletivas da Nação, a individualidade de hoje manifesta-se como um aprendente para toda a vida que é flexível". Neste sentido, a escola passa a ocupar um espaço que prepara os sujeitos para a vida, colaborando na constituição de um novo tipo de individualidade: do sujeito aprendente. Na mesma perspectiva de análise, Noguera-Ramirez (2011, p. 249) aponta o surgimento de uma forma de subjetividade contemporânea, por ele denominada de Homo discentis. Segundo o autor, tal figura subjetiva também se articula às características de um aprendiz permanente, flexível e ativo. 
Portanto, considerados tais arranjos, a aprendizagem tornou-se um objeto de pesquisa visando compreender que processos estão implicados nesta exaltação da aprendizagem e como tais articulações se desenrolam no cenário brasileiro. Ao final, buscase sustentar que os discursos sobre aprendizagem mobilizados no período investigado se articulam ora ao aprimoramento individual, ora ao ajustamento social e ora ao conceito de experiência, constituindo um saber pedagógico na transversal. Do mesmo modo, apesar da renovação educacional em curso no Brasil à época propor novos conceitos para o ensino e aprendizagem a partir do movimento escolanovista, tal renovação não descartava um tipo de condução pedagógica intencional.

\section{Renovar a educação é preciso: - Brasil nos anos 1930}

Após a descrição inicial de um cenário contemporâneo de exaltação da aprendizagem, mostrou-se necessário um mergulho histórico que auxiliasse na compreensão do mesmo. De acordo com Nagle (2015, p. 41), na análise do contexto educacional dos séculos XIX e Xx no Brasil, o Manifesto dos Pioneiros da Educação Nova (1932) (Azevedo et al., 2006) pode ser considerado um marco periódico para compreensão da história educacional brasileira. Segundo o autor, há um antes e um depois desta publicação. Por se tratar de um documento síntese das críticas educacionais efervescentes desde a década de 1920, o Manifesto dos Pioneiros da Educação Nova apresenta argumentos que um grupo amplo e diverso de intelectuais acreditava serem pontuais para uma reforma educacional a partir das mobilizações do movimento da Escola Nova no Brasil. Do mesmo modo, eventos como a chamada Revolução de 1930 e a urgente criação do Ministério dos Negócios da Educação e Saúde Pública (1930) instauram um novo momento histórico para a educação brasileira visando o projeto de modernização do país.

Durante a década de 1920, aconteceriam no Brasil inúmeras experiências isoladas de reformas educacionais em alguns estados específicos. Nagle (2009, p. 240) sugere que a década de 20 poderia ser caracterizada como a segunda fase do escolanovismo no Brasil, por se caracterizar como o momento "da difusão e das realizações". Assim, destaca que "O que se fez no Brasil, até 1920, foi simples preparação de terreno. A verdade é que não havia condições sociais e pedagógicas que estimulassem o desenvolvimento da nova forma de entender a escolarização". Portanto, percebe-se que há indícios de uma renovação pedagógica, por uma série de movimentos ainda no século
XIX e na efervescência da Proclamação da República (1889). Mas é a partir da década de 1930 que essas experiências se potencializam e passam a operar de forma articulada a um arranjo nacional.

Outro ponto importante na atmosfera reformista do início do século xx está no caráter particular que o movimento da Escola Nova teve no Brasil. Nagle (2009, p. 263) destaca que no Brasil houve praticamente uma sincronia entre a propagação das ideias e as mudanças institucionais comprometidas com a corrente escolanovista. Para o autor, a conexão entre o escolanovismo e a educação pública brasileira se torna possível por uma característica singular do caso brasileiro: as suas iniciativas, ao contrário das experiências de dimensão universal, foram de caráter público e estatal (Nagle, 2009). Assim, identifica que expoentes da renovação educacional como Lourenço Filho, Anísio Teixeira e Fernando de Azevedo², por exemplo, ocupavam cargos públicos na área educacional e mobilizam o ímpeto reformista a partir dos espaços que ocupavam no momento.

Após estes apontamentos, tornou-se possível enxergar as influências deste movimento no Estado brasileiro $^{3}$ e delimitar a Revista Brasileira de Estudos Pedagógicos como uma materialidade potente para compreender como são introduzidas no contexto brasileiro novas conceituações direcionadas ao ensinar e ao aprender. Neste sentido, destaca-se a criação do Instituto Nacional de Estudos Pedagógicos (INEP) ${ }^{4}$ e, posteriormente, em 1944, da Revista Brasileira de Estudos Pedagógicos (RBEP) ${ }^{5}$. Seguindo estudos elaborados por Rothen (2005, p. 189), pontua-se que o INEP foi "um órgão estatal utilizado pelos escolanovistas para exercer a liderança intelectual na elaboração e implantação de políticas para a educação". Criado em 1938 pelo decreto-lei n ${ }^{\circ} 580$ como um órgão vinculado ao Ministério da Educação e Saúde, em sua história "constitui-se como um órgão autônomo que buscou exercer a liderança intelectual das reformas educacionais brasileiras" (Rothen, 2005, p. 190). Segundo

2 De acordo com Cunha (2010b, p.264) tais reformas educacionais em nível estadual podem ser exemplificadas com Lourenço Filho no Ceará; Anísio Teixeira na Bahia; Francisco Campos em Minas Gerais e Fernando de Azevedo no Distrito Federal.

3 Cury (1984) aprofunda a discussão em torno das disputas do projeto educacional brasileiro na década de 1930, travada entre o grupo dos escolanovistas e dos intelectuais católicos. Tal discussão é importante para evidenciar que a proposta das reformas se deu em um cenário de disputas não linear e, por vezes, contraditório.

4 Atualmente, o INEP é denominado de Instituto Nacional de Estudos e Pesquisas Educacionais Anísio Teixeira.

5 Sigla para designar Revista Brasileira de Estudos Pedagógicos. 
o autor, a partir de 1944, o INEP também cria a RBEP "como um instrumento para a divulgação da sua produção intelectual e para influenciar a formação das concepções brasileiras de educação".

Portanto, ao evidenciar o escolanovismo como um movimento que introduz novas possibilidades para o ensinar e o aprender, a RBEP, como um instrumento de liderança intelectual desse grupo, se mostra pontual para evidenciar as articulações que delineiam essas redefinições. Ao localizar a RBEP no arquivo, busco lê-la como um instrumento que torna possível que certas coisas sejam enunciadas e não outras: "O arquivo é, de início, a lei do que pode ser dito, o sistema que rege o aparecimento dos enunciados como acontecimentos singulares" (Foucault, 2014, p. 158). Assim sendo, partindo da periodização sugerida por Rothen (2005), opto por iniciar o exercício investigativo seguindo as ênfases das gestões de Lourenço Filho e Murilo Braga (1944 a 1951) e Anísio Teixeira (1952 a 1964). A partir deste recorte, também delimito um recorte histórico para a análise (1944 a 1964), especialmente pelo interesse em compreender como dois expoentes do movimento escolanovista conduziram as publicações referentes à Pedagogia e à educação neste contexto histórico específico.

Entretanto, não se tem por objetivo compreender tais períodos de forma personalizada, mas sim como um movimento que se fortalece dentro de um contexto educacional renovador na esfera estatal. Neste sentido, Veiga-Neto (2011, p. 61) pontua que as forças não estão nas mãos de alguns atores ou de algum grupo, mas "tais forças estão distribuídas difusamente por todo o tecido social". Portanto, é nesta perspectiva que se percebe um cenário de emergência, uma vez que "Trata-se, então, de uma novidade possível somente num determinado estado de forças e, por isso mesmo, particular, única e histórica" (MarínDíaz, 2012, p. 31).

Ao propor a sinalização da emergência de novos conceitos educacionais no Brasil, a partir de um mergulho histórico específico, não se teve por objetivo apontar uma descoberta datada. Aliada a Foucault (2010, p. 112), propõe-se uma busca "pelas condições de possibilidade do aparecimento, da construção, do uso regrado de um conceito no interior de uma formação discursiva". Dessa forma, ao descrever um cenário histórico específico, sinalizo a compreensão da emergência "como acontecimento discursivo" (Marín-Díaz, 2012, p. 31), remetendo à racionalidade e às suas respectivas condições de possibilidade. Deste modo, ao evidenciar a naturalização e a própria proliferação discursiva da aprendizagem no presente, sugiro a análise de um momento histórico de centralidade na educação que, ao propor novos conceitos para o ensinar e o aprender, talvez sinalize aspectos importantes para compreender as novas ênfases educacionais na contemporaneidade.

\section{Percursos metodológicos na RBEP}

Após a delimitação da materialidade analisada, foram elaborados cinco exercícios de sistematização das 90 edições da RBEP, que serão brevemente descritos na continuidade. Tais exercícios compuseram o modo de exploração e sistematização da materialidade pesquisada. Assim, cada movimento se caracterizava por um tipo de aprofundamento da pesquisa, marcado por uma busca intencional nos materiais e, também, indicando possibilidades para os próximos passos desta organização. 0 primeiro movimento com os materiais analisados desenhou-se a partir de uma visão panorâmica da distribuição da Revista dentro das respectivas gestões institucionais inicialmente citadas. Esta organização teve como objetivo um mapeamento amplo e temporal das publicações em análise. Neste movimento, as revistas foram organizadas em grandes quadros por anos.

Na gestão de Lourenço Filho/Murilo Braga (19441951) foram publicadas 44 edições da RBEP de forma aleatória. Por exemplo, no ano de 1946 foram publicadas 9 edições, enquanto que nos anos de 1948, 1949 e 1950, foram editados apenas 3 exemplares anuais. Já na gestão seguinte, liderada por Anísio Teixeira (1952-1964), foram publicadas um total de 46 revistas, também de forma aleatória, pois nos anos de 1960, 1961 e 1962, foram editadas apenas duas revistas anuais. Nos demais anos da citada gestão, foram publicadas 4 edições anuais da RBEP.

Após esta rápida sistematização, elaborou-se um segundo movimento de organização, buscando pelos sumários individuais de cada uma das Revistas. Este amplo mapeamento teve como objetivo verificar se os sumários se mantiveram iguais ao longo dos vinte anos analisados. Assim, se iniciou um aprofundamento em edições que seriam mais interessantes para a análise proposta. Depois de verificar estes aspectos, foi elaborado um quadro em que são descritos estes sumários, destacando mudanças e regularidades no período em questão. Da mesma forma, após esta análise, foi eleita a seção Ideias e Debates como o foco principal de investigação. Para esta delimitação, a principal justificativa foi de que nesta seção encontravam-se os artigos dos principais intelectuais da educação à época, muitos deles com grande envolvimento na causa da renovação educacional no país. Cada edição da Revista apresentava de quatro a seis artigos na seção Ideias e Debates. Tais artigos, 
como ilustra o quadro a seguir, foram escritos por intelectuais de áreas variadas e buscavam refletir sobre experiências brasileiras e estrangeiras, bem como sobre tópicos teóricos variados:

Quadro 1: Recorte do sumário

da RBEP (Teixeira, 1958)

\section{SUMARIO}

Nowas o deass:

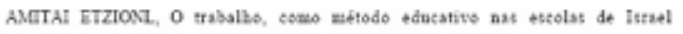
ELISA DLAS VELOSO, Foblemss de ayentameste a veola

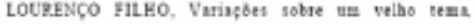

A opção por esta seção, como destacado anteriormente, se deu pelas publicações de expoentes do movimento de renovação educacional. Assim, mesmo considerando as demais seções da Revista profícuas para a análise, foi realizada uma escolha buscando sintonia com o problema de pesquisa proposto. Após estas definições, o foco passou aos artigos da seção escolhida, buscando definir quais aqueles que seriam mais pertinentes de serem analisados.

Portanto, no terceiro movimento foi feito um exercício de organização dos artigos por anos (de 1944 a 1964). Após este movimento, foi possível enxergar com maior clareza algumas possibilidades analíticas com estes materiais. Entretanto, mesmo com variados recortes, a pesquisa ainda carecia de um foco mais preciso para delimitar recortes qualificados. Portanto, foi estipulado um quarto movimento. Neste arranjo, os artigos selecionados no movimento anterior foram sistematizados em grupos temáticos, considerando sua respectiva organização, relevância e tema abordado. Ao definir estes grupos, os artigos escolhidos compuseram quatro categorias temáticas distintas. Foi a partir desta sistematização, apresentada a seguir, que foi possível delimitar os últimos recortes.

Quadro 2: Agrupamentos temáticos dos artigos

\begin{tabular}{|l|l|}
\hline & Descrição do tipo de material agrupado \\
\hline Grupo 1 & $\begin{array}{l}\text { Artigos relacionados especificamente } \\
\text { aos campos da Biologia, da Saúde e da } \\
\text { Psicologia. }\end{array}$ \\
\hline Grupo 2 & $\begin{array}{l}\text { Artigos relacionados Especificamente à } \\
\text { mensuração, testes, Exames, adaptação } \\
\text { e/ou inadaptação escolar de anormais/ } \\
\text { deficientes. }\end{array}$ \\
\hline Grupo 3 & $\begin{array}{l}\text { Artigos relacionados Especificamente } \\
\text { à Educação: relações da Educação com } \\
\text { o momento histórico e as inspirações } \\
\text { conceituais da RBEP. }\end{array}$ \\
\hline Grupo 4 & $\begin{array}{l}\text { Artigos relacionados especificamente à } \\
\text { Pedagogia e aos saberes pedagógicos. }\end{array}$ \\
\hline
\end{tabular}

Dito isto, sinalizo que o grupo eleito para a análise foi o n⿳⺈-Artigos relacionados especificamente à Educação: relações da educação com o momento histórico e as inspirações conceituais da RBEP- pois se entendeu que, dentre as temáticas sistematizadas, este grupo de materiais seria o mais adequado para auxiliar a responder à problematização mobilizadora. Assim, ao definir um grupo específico de artigos para serem explorados, foi elaborado o quinto movimento de exploração dos materiais. Após aprofundamento de todos os artigos que compunham o grupo escolhido para análise, foram escolhidos 14 artigos que seriam o corpus analítico, como destacado no quadro a seguir:

Quadro 3: Corpus analítico ${ }^{6}$

\begin{tabular}{|c|c|c|c|}
\hline & ANO & $\begin{array}{c}\text { ARTIGOS } \\
\text { SELECIONADOS }\end{array}$ & $\begin{array}{c}\text { EDIÇÃO } \\
\text { RBEP }\end{array}$ \\
\hline \multicolumn{4}{|c|}{ Gestão Lourenço Filho/Murilo Braga (1944-1951) } \\
\hline №1 & 1945 & $\begin{array}{l}\text { Conceito biológico } \\
\text { de educação - Faria } \\
\text { Góis Sobrinho }\end{array}$ & Vol. 3 Num. 7 \\
\hline №2 & 1945 & $\begin{array}{l}\text { Novos objetivos para a } \\
\text { educação no Brasil - } M \text {. } \\
\text { A. Teixeira de Freitas }\end{array}$ & $\begin{array}{l}\text { Vol. } 4 \\
\text { Num. } 12\end{array}$ \\
\hline №3 & 1946 & $\begin{array}{l}\text { O problema da } \\
\text { educação nacional - } \\
\text { Eurico Gaspar Dutra }\end{array}$ & $\begin{array}{l}\text { Vol. } 7 \\
\text { Num. } 19\end{array}$ \\
\hline №4 & 1946 & $\begin{array}{l}\text { Pragmatismo e educação/ } \\
\text { Origens do pragmatismo } \\
\text { - Adrian Rondileau }\end{array}$ & $\begin{array}{l}\text { Vol. } 7 \\
\text { Num. } 20\end{array}$ \\
\hline \multicolumn{4}{|c|}{ Gestão Anísio Teixeira (1952-1964) } \\
\hline №5 & 1953 & $\begin{array}{l}\text { A filosofia da educação } \\
\text { de Dewey - William } \\
\text { Heard Kilpatrik }\end{array}$ & $\begin{array}{l}\text { Vol. } 19 \\
\text { Num. } 49\end{array}$ \\
\hline №6 & 1954 & $\begin{array}{l}\text { A educação que nos } \\
\text { convém - Anísio Teixeira }\end{array}$ & $\begin{array}{l}\text { Vol. } 21 \\
\text { Num. } 54\end{array}$ \\
\hline №7 & 1955 & $\begin{array}{l}\text { Bases da teoria lógica de } \\
\text { Dewey - Anísio Teixeira }\end{array}$ & \begin{tabular}{|l|} 
Vol. 23 \\
Num. 57
\end{tabular} \\
\hline №8 & 1956 & $\begin{array}{l}\text { Caminhos que levam } \\
\text { à aprendizagem } \\
\text { - Riva Bauzer }\end{array}$ & $\begin{array}{l}\text { Vol. } 25 \\
\text { Num. } 61\end{array}$ \\
\hline №9 & 1956 & $\begin{array}{l}\text { Educação não é privilégio } \\
\text { - Anísio Teixeira }\end{array}$ & $\begin{array}{l}\text { Vol. } 26 \\
\text { Num. } 63 \\
\end{array}$ \\
\hline №10 & 1958 & $\begin{array}{l}\text { Educação - problema } \\
\text { da formação nacional } \\
\text { - Anísio Teixeira }\end{array}$ & $\begin{array}{l}\text { Vol. } 29 \\
\text { Num. } 70\end{array}$ \\
\hline №11 & 1960 & $\begin{array}{l}\text { John Dewey: uma } \\
\text { filosofia da experiência } \\
\text { - Newton Sucupira }\end{array}$ & $\begin{array}{l}\text { Vol. } 34 \\
\text { Num. } 80\end{array}$ \\
\hline
\end{tabular}

6 Todas as Revistas Brasileiras de Estudos Pedagógicos consultadas (do período de 1944 a 1964) estão disponíveis no acervo on-line do Instituto Nacional de Estudos e Pesquisas Educacionais Anísio Teixeira/INEP: <http://www.publicacoes.inep.gov. br/portal/subcategoria/1/page/15/item_page/10>Acesso em 12 dez. 2015. 


\begin{tabular}{|l|c|l|l|}
\hline & ANO & \multicolumn{1}{|c|}{\begin{tabular}{c}
\multicolumn{1}{c|}{ ARTIGOS } \\
SELECIONADOS
\end{tabular}} & \multicolumn{1}{c|}{$\begin{array}{c}\text { EDIÇÃo } \\
\text { RBEP }\end{array}$} \\
\hline №12 & 1962 & $\begin{array}{l}\text { Atualidade de Rousseau } \\
\text { - Lourenço Filho }\end{array}$ & $\begin{array}{l}\text { Vol. 38 } \\
\text { Num. 88 }\end{array}$ \\
\hline №13 & 1963 & $\begin{array}{l}\text { Estado atual da educação } \\
\text { - Anísio Teixeira }\end{array}$ & $\begin{array}{l}\text { Vol. 39 } \\
\text { Num. 89 }\end{array}$ \\
\hline №14 & 1963 & $\begin{array}{l}\text { A educação em face } \\
\text { da segunda revolução } \\
\text { industrial - Tomás } \\
\text { Maldonapo }\end{array}$ & $\begin{array}{l}\text { Vol. 40 } \\
\text { Num. 92 }\end{array}$ \\
\hline
\end{tabular}

Assim, os artigos selecionados foram mapeados, buscando questões relativas à aprendizagem, ao aprender e ao ensinar, por exemplo. Depois de um exercício recorrente de escolhas e descartes, passaram a ser destacadas as recorrências nos materiais analisados, visando a composição das categorias analíticas. Posteriormente, tais combinações resultariam em três grupos distintos: psico-biológico (aprendizagem como aprimoramento individual); sociológico (aprendizagem como ajustamento social) e filosófico (aprendizagem como experiência). Tais grupos, ao final, encaminhariam as análises, que seguem delineadas a seguir.

\section{Tendências dos discursos sobre aprendizagem}

Apesar de identificar, a partir da análise da RBEP, algumas tendências dos discursos sobre aprendizagem, percebe-se que o movimento renovador escolanovista não é uniforme na propagação de seu ideário. De acordo com apontamentos de Pagni (2000) e Cunha (1999), a multiplicidade de interpretações e disputas em torno da Educação a partir do início do século XX no Brasil, apesar de se concentrar em torno de um movimento, não é linear. Na RBEP, há influências características e predominantes no que tange às inspirações teóricas que mobilizam os estudiosos que a compõem. Entretanto, apesar destas predominâncias, há uma variedade de apropriações e interpretações do movimento escolanovista e do próprio pragmatismo, especialmente da vertente norte-americana.

Cunha (1999, p.42) argumenta que "o escolanovismo brasileiro, por tratar-se de um movimento de longa duração, desenvolveu múltiplas formas de compreender e solucionar os problemas educacionais". Nesta perspectiva, Cunha (1999) destaca que no movimento renovador havia uma vertente tecnicista e uma vertente ancorada em uma direção praticamente oposta, especialmente pela inspiração no pragmatismo de John Dewey. No Brasil, o principal propagador desta segunda vertente foi Anísio Teixeira e, por tal razão, seus textos aparecem com força nesta pesquisa. Este esclarecimento é importante, pois as análises aqui estabelecidas focam-se mais especificamente na segunda vertente acima descrita, denominada por Cunha (2000) de a segunda face do escolanovismo brasileiro. Segundo o referido autor, esta segunda vertente se diferencia da primeira especialmente por um maior equilíbrio entre aspectos sociais e individuais.

A aprendizagem compreendida como aprimoramento individual está diretamente articulada a este tipo de interpretação. Percebe-se que a articulação dos discursos biológicos e psicológicos pressupõe um tipo de normalidade. Entretanto, esta normalidade não ignora as influências de ordem cultural e social que agem, modificam e constituem os grupos humanos. Neste sentido, destaca-se que a ideia de aprendizagem como aprimoramento individual mostrou-se marcada, ao longo das análises, pela ligação direta com a compreensão da aprendizagem como um tipo de ajustamento social. Entretanto, o que parece diferenciar estas duas frentes interpretativas é que o aprimoramento individual, apesar de estar substancialmente articulado ao ajustamento social, é um tipo de aprendizagem que acaba por se caracterizar como um pré-requisito sem o qual esta outra forma de aprendizagem não se efetivaria, pois o indivíduo, como apontam os excertos abaixo, necessita estar ligado ao socius.

Portanto, uma das marcas educacionais que o movimento escolanovista imprime aos discursos sobre aprendizagem é do aperfeiçoamento dos indivíduos para ajustarem-se às novas demandas da sociedade. Assim, "As pressões por um tipo de educação condizente com a industrialização levavam à procura de um ensino mais prático, voltado para o desenvolvimento de habilidades exigidas para transformações concretas" (Schwartzman, Bomeny e Costa, 2000, p. 74). Este aperfeiçoamento, por sua vez, tem a aprendizagem como um mecanismo de efetivação e sugere um tipo de autocondução guiada pelo constante exercício de melhoramento dos indivíduos.

Esta autocondução aprimorada insinua-se a partir do entendimento da aprendizagem como um mecanismo que ensine aos indivíduos a liberdade de praticar e se autogovernar. Entretanto, apesar da aprendizagem objetivar o aprimoramento do indivíduo, este exercício não está ligado a uma lógica individualista, mas a uma preparação para a vida em sociedade. Portanto, o aprimoramento individual está articulado ao melhoramento do indivíduo para uma vida coletiva. E este aprimoramento, ao se utilizar da aprendizagem como um mecanismo de efetivação, 
Quadro 4: Aprendizagem para aprimoramento individual

O ótimo da educação assim entendida implica ortogenia, desenvolvimento perfeito, aquele que realize a expressão melhor da criatura. 0 que tudo se resumiria no seguinte conceito incisivo: educar é fazer viver mais e melhor, tomada aqui a expressão em seu legítimo sentido de vida útil, idealista, enriquecida, pautada pelos mais autênticos valores morais. Como foi dito, a educação realiza tais objetivos pela aprendizagem. Esta é seu mecanismo essencial e definidor. (Sobrinho, 1945).

As relações dos homens entre si e com seu meio adquirem um novo nível, dominado por símbolos e "sentidos", que têm de ser aprendidos e adquiridos, para a necessária integração social. Tal transformação importa em fazer que o comportamento biológico se torne um comportamento intelectual. E não só importa. 0 meio social agora o exige. 0 comportamento puramente biológico indica, antecipa operações intelectuais, mas não as exemplifica. (Teixeira, 1955).

Sem dúvida, a ação educativa, se bem compreendida e exercitada, tem o efeito de propiciar a manifestação mais cabal dos bons atributos do ser, que emergem do potencial nativo, o genótipo, o patrimônio hereditário, afeiçoando essas virtualidades a uma expansão plena do espírito, e acrescendo-as das incorporações de conhecimentos e formas de conduta consideradas úteis a boa ambientação do indivíduo como socius, como participante do agregado social. (Sobrinho, 1945).

condiciona o indivíduo a melhorar pela prática contínua desses modos de condução.

A partir de análises tecidas por Silva (2015), ao aprofundar-se especificamente no discurso eugênico no Brasil entre os séculos XIX e XX, pontua-se a emergência de uma nova forma de saber articulada pelos discursos de cunho biológico. Tais discursos, de acordo com autor, instituem uma postura biodeterminista: "o discurso biológico vai se instituindo como uma forma de poder-saber fundamental para as novas 'verdades' que deveriam guiar os rumos da sociedade" (Silva, 2015, p. 18). Esta postura biodeterminista também se manifesta de forma considerável pelo discurso psicológico propagado pela RBEP. Assim, pressupõe-se certa normalidade biológica que precisaria ser aprimorada para a vida em sociedade.

Na mesma perspectiva analítica, Hillesheim e Guareschi (2007) indicam que o processo de individualização do espaço escolar para o aprimoramento das condutas individuais se dá, também, pelo advento da Psicologia. De acordo com as autoras, "O saber psicológico vem dar conta da tarefa de classificar e controlar os seres humanos, visto a preocupação com determinados aspectos da conduta humana, que passaram a serem compreendidos como problemáticos" (Hillesheim e Guareschi, 2007, p. 82). É neste sentido que as aptidões individuais são melhoradas visando o ajustamento social. Para Noguera-Ramirez (2011, p. 241), os elos entre os campos da Pedagogia e Psicologia também foram possíveis pela "virada na forma do governamento pedagógico: a crítica à escola e à "pedagogia tradicional", a defesa dos direitos e necessidades da criança pode ser facilmente percebida como parte de uma mudança na estratégia de governamento".
Na atmosfera deste ideário educacional em análise, o aperfeiçoamento individual é uma atividade com foco na vida em sociedade e justificado segundo uma perspectiva democrática. Rose (2011), ao situar a Psicologia Social do início do século Xx, salienta a reiterada relação deste campo de saber específico com o ideário democrático deste momento histórico. De acordo com o autor, "governar cidadãos de maneira democrática significa governa-los através de suas liberdades, escolhas e solidariedades, e não apesar delas. Significa fazer dos sujeitos, de suas motivações e inter-relações [...] aliados do governo" (Rose, 2011, p. 164). Conforme apontamentos do autor, a formação de sujeitos para a vida democrática estaria intrinsicamente relacionada ao aperfeiçoamento dos indivíduos e do melhoramento de sua capacidade de condução individual. Este aperfeiçoamento individual, por sua vez, implicaria uma maior capacidade em uma sociedade democrática: para o trabalho e para o convívio, por exemplo. Nesse sentido, a condução individual não anula ou exclui a participação de vida social, mas a qualificaria.

A aprendizagem para o ajustamento social, compreendida dentro de um cenário de disputas no movimento escolanovista brasileira, destaca-se por uma perspectiva interpretativa pontual. Cunha (2000), ao apontar a hegemonia da vertente tecnicista que se sobressaiu no Brasil, defende que esta perspectiva não tem relações com as defesas empreendidas por parte do movimento renovador mais articulado a uma vertente deweyana. A denominada segunda face do movimento (Cunha, 2000), comprometida com uma interpretação do pragmatismo norte-americano e principalmente das ideias educacionais de John Dewey, articula uma relação intrínseca que deveria 
resultar da obra educacional: o aperfeiçoamento individual para o ajustamento social.

A perspectiva deweyana da educação renovada busca uma relação de equilíbrio entre estes polos que a compõem: "valorizar os aspectos psicológicos individuais sem desviar a escola de suas funções socializadoras" (Cunha, 2000, p. 53). Em outra reflexão, Cunha (1994) salienta que o ideário renovador desta segunda face do escolanovismo foi marcado por uma dupla natureza. Também esclarece que o fim do movimento da Escola Nova não era o indivíduo: "Todo o esforço dos escolanovistas em prol da observação das peculiaridades individuais é norteado pela ideia da conquista de uma sociedade harmoniosa por intermédio da escola" (Cunha, 1994, p. 68). A Psicologia que sustenta alguns elementos do movimento renovador no Brasil também se articula ao que Rose (1998, p. 35) denomina de governo da subjetividade. Esta noção de governo, segundo o autor, define "uma certa forma de buscar a realização de fins sociais e políticos através da ação, de uma maneira calculada, sobre as forças, atividades e relações dos indivíduos que constituem uma população" (Rose, 1998, p. 35). Assim, a Psicologia como instrumento de intervenção para fins sociais está diretamente articulada à resolução de demandas sociais, pois "a subjetividade se tornou um recurso na administração dos problemas da nação" (Rose, 1998, p. 35).

Como indicam alguns elementos dos excertos abaixo, a formação deste "novo" cidadão brasileiro visava atender às particularidades individuais, porém com objetivos e aspirações comuns. Estes objetivos comuns, por sua vez, caracterizavam um projeto de abrasileiramento da nação através dos programas escolares renovados. A formação deste novo sujeito abrasileirado e ajustado à nação está diretamente articulada a um tipo de eficiência social. De acordo com Cunha (2000), esta necessidade de eficiência está articulada ao signo da vida moderna que inspirava os movimentos da sociedade brasileira e que também inspiram esta renovação que então se desenhava.

A modelagem individual das novas gerações para a vida em uma sociedade democrática alia-se ao que Rose (1998) define como o governo da alma: "as ciências psicológicas estão intimamente envolvidas com programas, cálculos e técnicas para o governo da alma. $\mathrm{O}$ desenvolvimento, no século $\mathrm{xx}$, das ciências psicológicas abriu novas dimensões para o nosso pensamento". A renovação educacional, portanto, não tem por objetivo descartar a tradição educacional e social pré-existente, mas conduzir os sujeitos a novas formas aperfeiçoadas de autocondução, condizentes com o espírito da modernidade. 0 ajustamento social, nesta perspectiva, delimita que sujeitos aperfeiçoados e com uma boa capacidade de se autoconduzirem no espaço social proveriam as condições para uma vida em sociedade mais igualitária e justa.

Nesta perspectiva, Cunha (1994, p. 69), destaca que a "Psicologia, embora seja uma das ciências básicas da Escola Nova, não constitui, isoladamente das ciências sociais, o cerne do pensamento escolanovista". Desta forma, sugere que a Psicologia forneceu os meios necessários para que a escola renovada investigasse melhor as características infantis e fosse um local capaz de realizar plenamente os atributos de cada indivíduo (Cunha, 1994). Na mesma direção, Rose (2011, p. 109) argumenta que "Não é acidente que a Psicologia - enquanto uma linguagem, um conjunto de normas, um corpo de valores, uma coleção de técnicas, uma pletora de experts - exerça papel tão significativo nas tecnologias de governo das democracias liberais". Neste sentido, a escola mostrou-se um

\section{Quadro 5: Aprendizagem para ajustamento social}

Educação é o processo de crescimento baseado na experiência a condicionado pela aprendizagem, no sentido da integração do indivíduo e sua melhor adaptação ao meio físico, ao vicio vivo e ao meio social, e que, por sua devida generalização, conduz a um contínuo aperfeiçoamento do grupo. (Sobrinho, 1945).

O sistema de educação do estado democrático moderno, convém repetir, não é tal sistema (vigente até 1930 no país), mas de escolas públicas destinadas a oferecer oportunidades iguais ao indivíduo e ministrar-lhe educação para o que se costuma chamar de eficiência social, ou seja, o preparo para o exercício das suas funções sociais de cidadão, de trabalhador (concebido o termo sem nenhuma conotação de classe) conforme as suas aptidões e independente de suas origens sociais, e de consumidor inteligente dos bens materiais e espirituais da vida. (Teixeira, 1963).

Esses novos conceitos e aspirações não se concretizaram imediatamente. Os moldes antigos eram resistentes e todo o século dezenove foi uma luta por técnicas e processos novos, que permitissem a plena realização dos ideais escolares da democracia. Só muito lentamente é que a escola comum se emancipou dos modelos intelectualistas para dar lugar à escola moderna, prática e eficiente, com um programa de atividades e não de matérias, iniciadora nas artes do trabalho e do pensamento reflexivo, ensinando o aluno a viver inteligentemente e a participar responsavelmente da sua sociedade. (Teixeira, 1956). 
terreno fértil e prático para utilização da Psicologia como ferramenta de governo.

A aprendizagem como experiência, dentro desta trama analítica específica, sugere a articulação de uma ferramenta que operacionaliza os movimentos de aperfeiçoamento individual e do ajustamento social. Assim, apesar das tendências por ora descritas se alinharem às proposições educacionais renovadoras escolanovistas, não significa que a tarefa educativa estaria anulada. Segundo Noguera-Ramirez (2011, p. 247) "evidentemente, se tratava de um abandono da velha educação, mas não um abandono da própria ideia de educar". Assim, não há um descarte, mas um rearranjo "na dinâmica das forças: uma forma de governo que implique o menor investimento de forças, porém que garanta um governamento mais permanente e estendido" (Noguera-Ramirez, 2011, p. 247).

Apesar destes apontamentos, ao explorar as inspirações teóricas desta segunda face do escolanovismo no Brasil (Cunha, 2000), fortemente ancoradas em John Dewey, percebe-se que ele "não desenvolve explicitamente um conceito de aprendizagem, mas seu conceito de experiência educativa se confunde com o de aprendizagem e este, por sua vez, com os conceitos de crescimento, desenvolvimento e adaptação" (Noguera-Ramirez, 2011, p. 248). Assim, nesta grade interpretativa, a aprendizagem é uma ferramenta para alcançar outros objetivos. Portanto, a aprendizagem como experiência pode ser entendida como um tipo de aperfeiçoamento constante das conduções individuais, implicando uma postura educativa frente à vida, como exemplificam os excertos seguintes.
Para Dewey (1971, p. 86), uma experiência educativa se caracteriza pelo fornecimento de ferramentas que auxiliem o indivíduo a reagir, responder ou vivenciar de forma mais qualificada suas experiências futuras. Segundo o autor, "nenhuma experiência será educativa se não tender a levar - simultaneamenteao conhecimento de mais fatos, a entreter e a melhor e mais organizado arranjo de fatos e ideias" (Dewey, 1971, p. 86). É nesta perspectiva, portanto, que John Dewey esboça um conceito de aprender: trata-se de algo que decorre da experiência. Portanto, não se deve considerar a experiência pela sua extensão ou quantidade, mas pela sua qualidade. Assim, destaca que há diferenças de caráter qualitativo entre as experiências que podem ser educativas, não-educativas e/ou deseducativas, por exemplo (Dewey, 1971).

Apesar dos entrelaçamentos apontados entre a experiência e o aperfeiçoamento individual, Dewey (2007, p. 63) salienta a necessária relação com o que denomina de fator social. "Quando o fator social está ausente, a aprendizagem se torna uma transformação de algum conteúdo apresentado numa consciência simplesmente individual, e não existe uma razão intrínseca para que a transformação dê à predisposição mental e emocional uma orientação mais social". (Dewey, 2007, p. 63). Ao tecer a crítica ao seu próprio contexto educacional e econômico, Dewey (2001, p. 190) sustenta que as escolas estariam educando os sujeitos na perspectiva de um individualismo cru. Para o autor, as novas sociedades industrializadas de seu tempo difundiam a ideia de serem economicamente livres e, consequentemente,

\section{Quadro 6: Aprendizagem como experiência}

\footnotetext{
A linguagem e o meio cultural fazem, por fim e assim, do homem o ser raciocinante, o animal racional de que falava Aristóteles. As suas necessidades e as suas dificuldades fazem-se problemas, que são resolvidos pelas instituições, pelos hábitos, pelas crenças, pelas artes e pelos conhecimentos, que construiu e obteve no seu processo de experiência, de tal modo transformado em um processo contínuo de investigação, aprendizagem e descoberta. (Teixeira, 1955).

Que significado deve então o conceito dinâmico dar ao verbo aprender? Dewey é explícito. A definição decorre do ato de experiência. Aprender bem significa capacidade de reter de uma experiência algo que sirva para vencer as dificuldades de uma experiência posterior. A concepção antiga, tal como a vimos, procurava dar como lições, matérias ou conclusões formuladas por outrem, fazendo-as decorar. [...]. Portanto, a escola deve trabalhar com coisas e não apenas confiar em livros, e —isso é muito importante- as coisas devem entrar em ação, ser postas em uso, de maneira fecunda a fim de dirigir a formação de disposições mentais e morais. (Kilpatrik, 1953).

Conhecer, saber é, assim, uma operação, uma ação que transforma o mundo e lhe restaura o equilíbrio. Estou agora seguro, sei, voltei à tranquilidade e posso dar livre curso à vida. A situação indeterminada tornou-se determinada, ficou sob controle, em virtude do conhecimento que adquiri. Saber, assim, não é aprender noções já sabidas, não é familiarizar-se com a bagagem anterior de informações e conhecimentos; mas, descobri-las de novo, operando como se fôssemos seus descobridores originais. [...]. O conhecimento, pois, é o resultado de um processo de indagação. (Teixeira, 1955).
} 
lugares em que se promoveria a liberdade igualitária de todos os indivíduos. Entretanto, Dewey (2001) ressalta que esta liberdade de fato não existiu ou foi bastante precária. É nesta dimensão que suas análises educacionais sustentam um caráter utópico que, de acordo com Pagni (2000), são especialmente difundidas e apropriadas no movimento escolanovista brasileiro por Anísio Teixeira.

Assim, Pagni (2000) destaca que a função educacional, para Anísio Teixeira, está diretamente articulada ao objetivo social: "o pensamento e a ação humanos perderiam sua qualidade individual para tornar-se eminentemente social, obrigando a educação a reverter-se sobre si mesma, tentando refletir as relações entre natureza e vida, não apenas individual, mas social". (Pagni, 2000, p. 298). 0 processo contínuo da experiência, portanto, não é exclusivamente individual, mas necessariamente social. E, do mesmo modo, a aprendizagem como experiência não tem relações somente escolares, mas educacionais, pois objetiva um aperfeiçoamento contínuo das conduções individuais e sociais.

\section{Conclusões}

Finalizando, gostaria de retomar a afirmativa que inicialmente apresentei como a ideia central a ser sustentada pelo exercício argumentativo deste artigo: o movimento escolanovista introduziu diferentes compreensões acerca da aprendizagem visando uma renovação educacional no Brasil. Entretanto, tais apreensões não descartavam um tipo de condução pedagógica intencional, diferentemente de tendências pedagógicas atuais, marcadas por processos de naturalização e individualização da aprendizagem.

Assim, pontuo que apesar de críticas atuais conectarem a exaltação da aprendizagem às pedagogias progressistas e às influências do movimento da Escola Nova, percebo que o movimento escolanovista no Brasil e os movimentos posteriores de críticas à "escola tradicional" merecem estudos e pesquisas que aprofundem seus impactos e problematizem seus desdobramentos no Brasil. Dito isso, ao visualizar os resultados obtidos por este exercício analítico e identificar saberes pedagógicos articulados como um nexo entre diferentes campos de saber, torna-se possível afirmar que estas tendências pedagógicas não têm relações diretas e simétricas com os discursos do presente sobre a aprendizagem.

Entretanto, pela crítica radical que tecem em relação à dita "escola tradicional" e aos modos de ensinar e aprender a ela articulados, talvez estes movimentos possibilitaram condições discursivas para que, no curso histórico recente, tais saberes pedagógicos fossem gradativamente esmaecidos, como é possível de ser observado no presente pelos processos inicialmente descritos e exemplificados. A aprendizagem, entendida como um efeito das conjunturas econômicas, políticas e históricas atuais, está articulada às demandas subjetivas do seu tempo, marcadamente individuais. Por outro lado, as proposições renovadoras, destacadas a partir destas análises, por se alinharem a outros campos disciplinares, aparentemente parecem descartar o saber pedagógico.

Como busquei evidenciar, a face deweyana do escolanovismo brasileiro vislumbrou novos modos de condução em que a escola talvez pudesse ampliar seu caráter formativo, não apenas ensinando conteúdos, mas, junto a eles, experimentando novos modos de conduções para os sujeitos. Entretanto, apesar de sua crítica ao modelo escolar vigente à época, evidencia-se a preservação do saber pedagógico e da necessidade de condução dos sujeitos escolares, diferentemente das tendências pedagógicas atuais. Portanto, é nesta perspectiva que encerro retomando a afirmativa central do artigo: na conexão entre diferentes campos de saber (Psicologia, Biologia, Filosofia, Sociologia, Pedagogia), há a preservação do lugar da condução intencional, bem como das relações entre os aspectos sociais e individuais, pois o movimento em curso no Brasil à época aqui analisada não pressupõe que a aprendizagem seja algo que possa ocorrer naturalmente. Desta forma, compreende-se que há diferenças entre as concepções de aprendizagem introduzidas pela Escola Nova no Brasil e as perspectivas atuais que têm fomentado a educação brasileira.

\section{Referências}

Azevedo, F. de, Sampaio, A., Teixeira, A., Lourenço Filho, M., Pinto, R. y Frota, J. (2006). Manifesto dos Pioneiros da Educação Nova. (1932). a reconstrução educacional no Brasil - ao povo e ao governo. Revista Histebr On-line, (especial), 188-204. Disponível em http://www.histedbr.fe.unicamp.br/revista/edicoes/22e/doc1_22e.pdf

Biesta, G. (2013a). The beautiful risk of education. London: Paradigm Publishers.

Biesta, G. (2013b) Para além da aprendizagem: educação democrática para um futuro humano. Belo Horizonte: Autêntica.

Cunha, M. (1994). A dupla natureza da Escola Nova: Psicologia e Ciências Sociais. Cadernos de Pesquisa, 88, 64-71.

Cunha, M. (1999). Três versões do pragmatismo deweyano no Brasil dos anos cinquenta. Revista Educação e Pesquisa, 25(2), 39-55. 
Cunha, M. (2000). John Dewey, a outra face da Escola Nova no Brasil. Em P. Ghiraldelli (Org.). O que é filosofia da educação? Rio de Janeiro: DP\&A.

Cunha, M. (2010). Estado e Escola Nova na história da educação brasileira. Em D. Saviani (Org.). Estado e Políticas Educacionais na História da Educação Brasileira. Vitória: EDUFES.

Cury, C. (1984). Ideologia e educação brasileira: católicos e liberais. São Paulo: Cortez.

Dewey, J. (1971). Experiência e Educação. São Paulo: Nacional.

Dewey, J. (2001). Pode a Educação participar da reconstrução social? Currículo sem fronteiras, 1(2), 189-193.

Dewey, J. (2007). Democracia e educação: capítulos essenciais. São Paulo: Ática.

Foucault, M. (2010). Os anormais. São Paulo: Martins Fontes.

Foucault, M. (2014). A arqueologia do saber. Rio de Janeiro: Forense Universitária.

Hillesheim, B. e Guareschi, M. (2007). De que infância nos fala a Psicologia do desenvolvimento? Algumas reflexões. Revista Psicologia da Educação, 25, 75-92.

Kilpatrik, W. (1953). A filosofia da educação de Dewey. Revista Brasileira de Estudos Pedagógicos, 19, (49), 3-10.

Marín-Díaz, D. (2012). Autoajuda e educação: uma genealogia das antropotécnicas contemporâneas. Porto alegre: UFRGS, 491 f. Tese de Doutorado em Educação - Programa de Pós-Graduação em Educação, Universidade Federal do Rio Grande do Sul.

Nagle, J. (2009). Educação e Sociedade na Primeira República. São Paulo: Universidade de São Paulo/EDusP.

Nagle, J. (2015). O Manifesto dos Pioneiros e a História da Educação Brasileira. Revista Brasileira de Estudos Pedagógicos, 96 (especial).

Noguera-Ramirez, C. (2011). Pedagogia e governamentalidade ou da Modernidade como uma sociedade educativa. Belo Horizonte: Autêntica.
Pagni, P. (2000). Do Manifesto de 1932 à construção de um saber pedagógico: ensaiando um diálogo entre Fernando de Azevedo e Anísio Teixeira. Ijuí: UniJuí.

Popkewitz, T., Olsson, U. e Petersson, K. (2009) Sociedade de aprendizagem, cosmopolitismo, saúde pública e prevenção à criminalidade. Educação \& Realidade, 34(2), 73-96.

Rose, N. (1998) Governando a alma: a formação do eu privado. Em: Silva, Tomaz T. da. Liberdades reguladas: a pedagogia construtivista e outras formas de governo do eu. Petrópolis, RJ: Vozes.

Rose, N. (2011). Inventando nossos selfs: psicologia, poder e subjetividade. Petrópolis, RJ: Vozes.

Rothen, J. (2005). O Instituto Nacional de Estudos Pedagógicos: uma leitura da RBEP. Revista brasileira de estudos pedagógicos, 86(212), 189-224.

Schwartzman, S., Bomeny, M. e Costa, M. (2000). Tempos de Capanema. São Paulo: Paz e Terra.

Silva, L. da. (2015). Biopolítica, raça e nação no Brasil (18701945). Cadernos IHU Ideias, 13 (235), 1-40.

Sobrinho, F. (1945). Conceito biológico de educação. Revista Brasileira de Estudos Pedagógicos, 3(7), 44-54.

Teixeira, A. (1955). Bases da teoria lógica de Dewey. Revista Brasileira de Estudos Pedagógicos, 23(57), 3-27.

Teixeira, A. (1956). Educação não é privilégio. Revista Brasileira de Estudos Pedagógicos, 26 (63), 3-31.

Teixeira, A. (1958). Revista Brasileira de Estudos Pedagógicos, 30, (71).

Teixeira, A. (1963). Estado atual da educação. Revista Brasileira de Estudos Pedagógicos, 39, (89), 8-16.

Veiga-Neto, A. (2011). Foucault e Educação. Belo Horizonte: Autêntica. 